\title{
A Research on the Practice of Developing a Rural 'Magnet' School Model: Theoretical and Applied Aspects
}

\author{
B.A. Gazdiyeva ${ }^{1}$, M.V. Tavluy ${ }^{1}$, Z.Ye. Gabdullina ${ }^{1}$, A.A. Akhmetzhanova ${ }^{2}$, G.T. Fatkiyeva ${ }^{1}$ \\ ${ }^{1}$ Department of Russian Philology and Librarianship, Sh. Ualikhanov Kokshetau State University, Abay St., \\ 71 -020000, Kokshetau, Republic of Kazakhstan. \\ ${ }^{2}$ Department of Analytics, Monitoring and Evaluation, JSC Information-Analytic Center, Dostyk St., \\ 18 -010000, Nur-Sultan, Republic of Kazakhstan.
}

\begin{abstract}
:
The authors of this article present provisional results of the work on the research project "Developing and Inspiring Entrepreneurial and STEAM Education in Rural Schools of Kazakhstan" funded by the Ministry of Education and Science of the Republic of Kazakhstan. The project has a significant applied component. The key concepts of the research project correspond with the fundamental didactic principles which reflect the main directions of the work on ensuring accessible and equal educational opportunities for all citizens. One of the tasks of the educational sector of Kazakhstan is the development of rural schools the specificity of which is explained by their geographical and informational distance from administrative and educational centers, by a small number of students and by the temporary absence of a fair number of highly qualified teachers. The present article includes some promising proposals on the development of a 'magnet' school model in the framework of rural school development in Kazakhstan. The study is based on theories of L.S. Vygotsky and G. Gardner and didactic ideas on the integration of academic subjects, the formation of students' functional literacy, the development of high-level skills, the introduction of entrepreneurial and STEAM education into the practice of Kazakhstani schools, as well as the use of innovative ideas aimed at the comprehensive development of generation $\mathrm{Z}$ and planning of their future professional careers. The 'magnet' school model is being developed in accordance with the practice of OECD countries - leaders of the international PISA study. It is currently being tested and prepared for full-scale implementation into the educational process of Secondary School No. 33 of Tselinograd district in Akmola region. The school is situated in Rodina province and appears to be a platform for the research project realization.
\end{abstract}

Keywords - Accessible and Equal Opportunities, Personality Development, Rural School, STEAM, Entrepreneurship, Career Planning, 'Magnet' School.

\section{INTRODUCTION}

According to the National Educational Database (NEDB), there are 5,285 rural schools in the Republic of Kazakhstan, as of January 16, 2020. The current situation in the rural school education sector can be characterized by the following significant problems:
- insufficient competitiveness of rural school graduates at different stages of their education, social and professional adaptation;

- informational "isolation" of rural educational institutions, lack of the necessary professional orientation of children, their ignorance of the modern labor market trends and the array of future specialties, as well as their incomplete understanding of the prospects of employment after graduation.

In addition, as a result of studying the current situation and analytical processing of the research materials, the following problematic "zones" and issues requiring competent scientific and methodological solutions have been identified:

- insufficient number of highly qualified teachers, in particular teachers of the English language and physics;

- insufficient development of the information and communication infrastructure of schools, limiting the inclusion of rural students and teachers in the global educational process, characterized by the use of the didactic and technical content of innovative technologies, for example, e-learning, m-learning, etc.;

- lack of the selectivity of additional academic subjects corresponding to modern trends in world school education;

- unprofessional or ill-conceived image and advertising activities of rural educational institutions, etc.

Against the background of existing risks and problems, a 'magnet' school model is being developed by a team of researchers, including high school employees, dealing with issues of modern didactics and individual methods, as well as practitioners from Nazarbayev Intellectual School of Physics and Mathematics in Kokshetau and from a rural school, which is the basis of the project "Developing and Inspiring Entrepreneurial and STEAM Education in Rural Schools of Kazakhstan," funded by the Ministry of Education and Science of the Republic of Kazakhstan. This model will make it possible to improve the quality of rural school education and prepare competitive graduates, who have a good understanding of the modern labor market trends and intelligently plan for their future professional career.

The purpose of the study is to develop and test a mechanism for the formation and development of entrepreneurial and STEAM education in rural schools in Kazakhstan. 
An individual hypothesis of the study was a conceptual idea presented by the following priority components:

1) the current personnel, material-technical, and informationcommunication state of rural schools can be changed due to the formation of a new school model, positioned as a magnet school [1,2], which has the specific features of a resource center - a support institution of the educational system that has a modern educational and production base providing training tools based on advanced technologies [3].

2) additional innovative programs offered by the 'magnet' school through a specialized focus or topic should be based on the "new set" of academic subjects that arouse the genuine interest of students - representatives of "generation Z". Such subjects include, first of all, academic disciplines from the spectrum of entrepreneurial and STEAM education;

3) actual work on the formation and testing of the 'magnet' school model can be carried out only on the basis of the existing rural school. Secondary School No. 33 (Rodina province) of Tselinograd district in Akmola region of the Republic of Kazakhstan was determined as such a base site. It is geographically surrounded by small schools and has launch opportunities for modeling the 'magnet' program.

The conceptual settings of 'magnet' schools are based on five pillars: diversity, an innovative curriculum, academic success, a quality educational system, and collaboration between family and society [4]. As part of the formation and implementation of the 'magnet' school program, project participants are expected to improve the overall quality of education, to contribute to the methodologically justified and intensive expansion of the zone of students' proximal development, and to increase the efficiency of the development of children's multiple intelligences. Currently, these issues are of particular importance.

For the moment, the research team is working on the following areas of preparation of the 'magnet' school program:

- compiling a school directory;

- carrying out full-scale advertising and image work;

- developing a feedback mechanism with parents;

- determining the "balance of opinions" of students and their parents when choosing a 'magnet' program, etc.

One of the important components of the 'magnet' school will be STEAM, which today is one of the main trends in world education. STEAM is based on a set of disciplines that are most in demand at the present stage and in the long term: $\mathrm{S}$ - science, $\mathrm{T}$ - technology, $\mathrm{E}$ - engineering, $\mathrm{A}$ - art, $\mathrm{M}$ - mathematics.

The main reasons for the rapid development of STEAM education in the world are as follows:

- the emergence of new professions related to high technologies (nano-, bio-, IT-technologies) and developing at the intersection of different sciences;

- the need for a full-scale and comprehensive training of highly qualified specialists who are able to adapt to the life and professional situation of any level of complexity and possess the skills of research and design work;

- the need to improve the teaching of the exact sciences and increase the motivation of schoolchildren and students in the study of mathematical disciplines as one of the foundations of the state's high-tech development.

The second 'magnet' direction in the project's basic school will be "Entrepreneurial Education". This direction is directly related to such important concepts as entrepreneurial culture the established set of principles, methods, and techniques of conducting entrepreneurial activity, complying with legal norms, ethical and moral principles; innovative culture is the process of mastering and introducing new knowledge and skills in various spheres of human life, in which the principle of continuity is maintained.

It should be noted that during the development of the application and the research project program (2017), the academic subject "Basics of Entrepreneurship" was not yet introduced in Kazakhstani schools. The initiators of the project in some sense "got ahead" of the educational program, proposing to introduce this course into the curriculum of Kazakhstani rural schools on the basis of monitoring the current situation and rigorous analytics. Today, Secondary School No. 33 of Tselinograd district is among the pilot general educational institutions with training classes on entrepreneurship.

This research study focuses on the development of rural schools in Kazakhstan in the context of their approximation to OECD standards. The results of the study help to reveal the general state of STEAM and entrepreneurial education in the world, to form the necessary scientific and methodically correct vision, as well as to develop a number of proposals for improving technical, mathematical, innovative and business education in Kazakhstani schools, in particular in rural schools.

The results of the study can be used by state and administrative structures in developing pedagogical and methodological models, as well as by the business sector and educational institutions - as a translation of the world experience. Methodological recommendations developed during the research work can be useful to school teachers, as they take into account the specifics of the development of a modern secondary school in Kazakhstan [5,6].

\section{MATERIAL AND METHODS}

The work is carried out at the methodological, scientifictheoretical and experimental-practical levels. The research methods used by the project participants are determined by the project's applied and interdisciplinary nature, which involves the use of general scientific and specific methods, including: exploration of the scientific and methodological base of the study; analysis; synthesis; observation (direct and participant); interviewing; questionnaire (using the questionnaire developed by the research team); mathematical statistics methods used in processing the results of questionnaires and interviews; interpretative methods providing a correct interpretation of the data obtained. Studying, analyzing and synthesizing the material obtained during the research work allows the project 
participants to derive a taxon, or an assessment, of the processed information and to offer their methodological product, expressed in the development of a mechanism for the formation of entrepreneurial and STEAM skills of rural school students, as well as in the elaboration of a 'magnet' school model based on a specific rural school.

\section{RESULTS AND DISCUSSION}

The work on the implementation of ideas for the integration of academic subjects and the acquisition of the status of a 'magnet' school by the rural educational institution is carried out in accordance with the plan of the project "Developing and Inspiring Entrepreneurial and STEAM Education in Rural Schools of Kazakhstan," which was originally built by experienced methodologists and innovative teachers included in the research team. An important part of the work at the first stage was the analysis and synthesis of the latest information, reflecting (1) the world experience in entrepreneurial and STEAM education (OECD countries with the best PISA results), and (2) scientific and methodological data related to the organization and functioning of magnet schools, whose program may include STEAM and entrepreneurial education. The results of this work are reflected in the analytical report "International Experience in the Development of Entrepreneurial and STEAM Education in OECD Countries" and in related methodological recommendations [5].

The most important recommendations include provisions reflecting the strategic development vector of Kazakhstani education in general and the prospects for the development of rural schools in the country in particular [7]. In this regard, the research project participants indicate the need to improve school curricula taking into account the components of STEAM education (developing strategic plans/strategies for schools to introduce STEAM technology programs in the educational process, increasing the level of integration of academic disciplines, introducing subjects related to the basics of science, entrepreneurship, financial literacy). This is particularly relevant, since currently in Kazakhstan there is no concept for the development of STEAM education at both the national and local levels. In this part of the paper, it is proposed to use the experience of the United States, one of the leaders in the development of 'magnet' schools and STEAM education.

Of particular importance is the development of continuity of school and university education - the opening of STEAM centers at Kazakhstani universities and the assignment of schools to universities, as, for example, at Brunel University (United Kingdom). In 2017, the corresponding center was opened in this educational institution involving students from nearby schools. Its activities are funded by the university, which is part of the social responsibility of higher education to society.

University-based centers are designed to increase the level of career guidance, which is currently not at a good enough level and may adversely affect the professional choice of graduates. In support of this recommendation, a career and leadership center was opened in Secondary School No. 33 of Tselinograd district, the purpose of which is to provide career guidance support for students (in accordance with their capabilities, abilities, achievements and with regard to the requirements of the modern labor market).

One of the prerequisites for the successful operation of the 'magnet' school is the modernization of the material and technical base of the educational institution, which is associated with the participation of community-minded business representatives who understand that the school is a "growth point" and finance bold initiatives and plans. In line with the work on the formation of the 'magnet' school model, a productive relationship has been established between the basic school, the university and business partners. A platform has been created for the development of entrepreneurial and STEAM education with the involvement of the academic and business community $[8,9]$. A modern chemistry room has been equipped in accordance with the latest technical, hygienic and didactic standards. In addition, as part of the implementation of the research project, a language laboratory has been created also with the support of business partners.

In our opinion, a serious step towards the promotion and development of entrepreneurial and STEAM education programs is to introduce schoolchildren to production, to organize student meetings with business community representatives - individual entrepreneurs, heads of farms, heads of LLPs and JSCs, and to establish contacts with participants in existing startups. According to the coordinators of the project "Developing and Inspiring Entrepreneurial and STEAM Education in Rural Schools of Kazakhstan," currently, such meetings are not held regularly in both urban and rural schools, and key performance indicators are not defined for such meetings. They suggest that the attention of interested parties should be drawn to the need for the development of additional training with a focus on entrepreneurial and STEAM education (organization of engineering, robotics, science, art, and language clubs; implementation of summer mathematical and language schools, open classrooms, thematic days; active implementation of the project work in the educational process, etc.). All this is proposed to be implemented as early as in elementary school.

The transformation of an ordinary school into a 'magnet' school with the content of a resource center requires teacher retraining at a new, modern and world-class, level. It is proposed to introduce the creation of an online portal into the range of directions and forms of advanced teacher training, which makes it possible to receive consultations of leading domestic and foreign methodologists, psychologists, business trainers, etc. in e-learning format. In addition, it is necessary to expand teachers' mobility programs, giving them the opportunity to visit the leading educational centers of the corresponding profile.

For several years, summer schools have been held in Secondary School No. 33 of Rodina province, combining university and school teachers, students, socially responsible entrepreneurs, and creative people for whom high-quality school education is one of the necessary conditions for the country's sustainable development. In 2018, the content of the summer school "You can STE@M it" was associated, amongst other things, with the initial testing of the ideas of the 'magnet' school - the 
realization of the content of STEAM and entrepreneurial education in practice.

In 2019, the summer school "Make it smART", which brought together students from two settlements (Rodina and Semenovka), was focused on the development of entrepreneurial and STEAM education. The working language of the summer school was English, and the priority goal of its implementation was to develop soft skills and language competence of rural school students. During the work of the summer school, psychological trainings, seminars on creative entrepreneurship and leadership development, as well as classes on learning foreign languages, namely English and Spanish, were held for rural school students. The summer school was supported by the Academy of Public Administration under the President of the Republic of Kazakhstan. The main speakers were graduates of the Bolashak Program (International Educational Scholarship of the President of the Republic of Kazakhstan).

The recommendations for the research sector "Entrepreneurial Education" were also presented in the analytical report "Monitoring and Evaluating Entrepreneurial and Innovative Culture of Rural School Students" [5]. These include, for example, the following:

- developing an electronic platform for teachers as an effective tool to increase methodological literacy in the field of entrepreneurial education;

- ensuring the continuity of entrepreneurial education at the school-college-university levels. However, financial training is not expected at the level of primary secondary education: at this stage, students need to build creativity, initiative, independence, and self-confidence, as well as develop the socalled "soft" skills. At the level of general secondary education, introducing the basics of financial literacy will contribute to the development of entrepreneurial skills and the improvement of students' financial literacy. In higher education, the development of entrepreneurial education should go through the creation and commercialization of developments, the launch of startups, spin-outs, etc.;

- involving schools in parallel initiatives that are carried out outside the school and also contribute to the development of entrepreneurial education;

- using the potential of the National Platform for Open Education in Kazakhstan, which will enable schools to participate in the implementation of the Open Master Class project (http://omc.moocs.kz/) that contains publicly accessible online courses of famous people of Kazakhstan, including entrepreneurs. Such work will not only stimulate the development of students' entrepreneurial skills, but also contribute to the digitalization of the school educational process.

One of the main objectives of the research project coordinators and the main points of the ethics code consists in the full transparency of the work, the continuous exchange of scientific and methodological experience with colleagues from the university and school environment of Kazakhstan and other countries, and the translation of work experience into the community of rural schools.
As part of the research, multivector seminars and webinars were held, reflecting the theoretical and applied aspects of the implementation of the research project on the formation of students' entrepreneurial and STEAM skills in the context of developing a rural 'magnet' school model:

- the methodological seminar "Prospects for the Development of Entrepreneurial and STEAM Education in Rural Schools" (February 2018);

- the methodological seminar focused on new approaches to teaching within the framework of the updated educational content and introducing STEM and STEAM technologies in the learning process (June 2018);

- the methodological webinar-seminar "Embedding Entrepreneurship Activities and Developing Its Culture in Kazakh Schools" (September 2018);

- the training seminar "Forming the Entrepreneurial Culture of Rural School Students: Research Experience” (June, 2019);

- the seminar "The Role of Teachers in the Formation of the Entrepreneurial Culture of Modern Students" (November 2019).

The seminars were attended by representatives of the academic university community: teachers, students and undergraduates of Sh. Ualikhanov Kokshetau State University; administration and teachers of Secondary School No. 33 of Rodina province in Tselinograd district; heads of the district education departments of Akmola and Kostanay regions; principals of rural schools. The speakers of the seminars and webinars were the head and coordinators of the project "Developing and Inspiring Entrepreneurial and STEAM Education in Rural Schools of Kazakhstan", Professor of Brunel University Abraham Altonayan (United Kingdom) as a foreign expert, Rector of the Academy of Public Administration under the President of the Republic of Kazakhstan, representatives of the National Chamber of Entrepreneurs of Kazakhstan "Atameken," as well as developers of a textbook on the basics of entrepreneurship for grades 10-11.

The content and provisional results of studying the ways and forms of work on the formation of entrepreneurial and STEAM skills, as well as on the creation of a rural 'magnet' school model based on the ideas of a resource center were presented by the head of the research project B. Gazdiyeva, Cand. Sci. (Philology), Associate Professor, at some significant conferences and forums:

- the report "Developing STEAM and Entrepreneurial Education in Rural Schools: the Case of Kazakhstan" at the Second Central Asian Research Forum on Sustainable Development and Innovation (first stage, March 2019, Loughborough University, United Kingdom), represented as an interdisciplinary research event that provides a platform for the development, discussion and implementation of science-based and action-oriented projects in the field of sustainable development (with an emphasis on the needs of the Central Asian region);

- the report "Advancing STEAM Education in Kazakhstan" within the framework of the second stage of the Central Asian 
Research Forum on Sustainable Development and Innovation (April 2019, Nur-Sultan, Kazakhstan);

- the report "Development of Entrepreneurial Skills of Rural School Students: Rodina Experience" at the International Scientific and Practical Conference of AEO Nazarbayev Intellectual Schools "Teachers Changing the School World" (October, 2019).

\section{CONCLUSIONS}

According to the World Bank, leading countries in education successfully use various modifications and methods of 'magnet' schools, which, in addition to basic curricula, implement additional education programs. The educational sphere of additional education is provided in this case by an indepth study of individual subjects and the expansion of the range of academic disciplines due to promising and soughtafter subjects.

Currently, Kazakhstani schools introduce new subjects into their curricula that ensure the formation of high-level skills needed for life in the society of the future: "Basics of Science", "Technology", "Engineering", "Robotics", "Basics of Entrepreneurship", etc. Particular attention is paid to promising ideas related to the development of STEAM and entrepreneurial education. The 'magnet' program of Secondary School No. 33 of Rodina province, which is the base platform for the research, includes these two areas.

As part of the implementation of the 'magnet' school program, an improvement is expected in the overall quality of education aimed at achieving the main goal of the educational process the formation of students' functional literacy.

The research (scientific project) "Developing and Inspiring Entrepreneurial and STEAM Education in Rural Schools of Kazakhstan" (No. AP05135242) is supported by a grant from the Ministry of Education and Science of the Republic of Kazakhstan.

\section{REFERENCES}

[1] Wang J, Herman J. Magnet schools: History, description, and effects. In R. Fox, N. Buchanan (Eds.), Handbook of school choice (pp. 158-179). New York, John Wiley and Sons, 2017.

[2] Tertiary education: The United Kingdom. www.web.worldbank.org

[3] Lebedintsev BB, Zapyataya OV. Rural school: infrastructure, educational process, place in society: practice-oriented almanac. Krasnoyarsk, 2008.

[4] Ballou D, Goldring E, Liu K. Magnet schools and student achievement. New York, National Center for the Study of Privatization in Education, 2006.

[5] Gazdiyeva BA, Akhmetzhanova AA, Sagyndykova ZhO, Tavluy MV, Fatkieva GT, Gabdullina ZYe, Aubakirova DS. International experience in the development of entrepreneurial and STEAM education in OECD countries: Analytical report. Kokshetau, Shokan Ualikhanov KSU Publishing house, 2018.

[6] Gazdiyeva BA, Akhmetzhanova AA, Sagyndykova ZhO, Tavluy MV, Gabdullina ZYe. Monitoring and evaluating entrepreneurial and innovative culture of rural school students: analytical report. Kokshetau, Publishing house 'Mir Pechati', 2019.

[7] Omarova NK, Sherembaeva RT. Sulfide copper ore flotation with «PS» reagent. Obogashchenie Rud. 2015;2:39-44.

[8] Sherembaeva RT, Omarova NK, Akimbekova BB, Katkeeva GL. Usage of new flotation agent "P" during sulfide copper ores flotation. Tsvetnye Metally. 2014;6:12-16.

[9] Sherembaeva RT, Omarova NK, Akimbekova BB, Mukhtar AA. Chalcopyrite and bornite flotation in hallimond tube. Tsvetnye Metally. 2016;4:8-11. 